\title{
DEVELOPING COMPREHENSIVE ASSESSMENT AND MONITORING PARAMETRES FOR LANDS IN SMALL TOWNS - FOCUS ON OBUDU TOWN, CROSS RIVER REGION, NIGERIA
}

\author{
Innocent A. Ugbong $1 \bowtie\left(D\right.$, Leonard E. Ukam ${ }^{2} \square$ \\ ${ }^{1}$ Department of Cadastre and Geo-engineering, Kuban State Technological University, Krasnodar City, \\ Russia. \\ ${ }^{2}$ Head, Department of Urban and Regional Planning, University of Cross River State, Calabar, Nigeria.
}

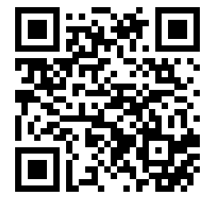

\section{ABSTRACT}

This paper attempts to develop techniques of examination and evaluation of urban land, for the purpose of determining the degree of comfortability and livability in small towns, using Obudu town as a focal point. The paper shows that, it is possible to allocate a number of natural (physical), man-made (anthropogenic) and public (social) performance indicators by which one can judge the quality of the urban environment and, consequently, about the extent of its comfort. An algorithm for a comprehensive assessment of urban land and Classification on the degree of comfort of the urban environment was formulated. The paper analyzes the prevailing conditions in the small town of Obudu, and proposes the methodology of assessing the degree of comfort of the urban environment using ten (10) to eight (8) natural and anthropogenic indicators.

Received 15 August 2021

Accepted 01 September 2021

Published 30 September 2021

\section{CorrespondingAuthor}

Innocent A. Ugbong,

inno_ugbong@yahoo.com

\section{DOI 10.29121/ijetmr.v8.i9.2021.1029}

Funding: This research received no specific grant from any funding agency in the public, commercial, or not-for-profit sectors.

Copyright: (C) 2021 The Author(s). This is an open access article distributed under the terms of the Creative Commons Attribution License, which permits unrestricted use, distribution, and reproduction in any medium, provided the original author and source are credited.

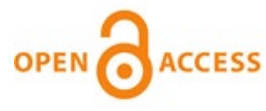

Keywords: Monitoring Parametres, Technogenesis, Urbanization, Degree of Comfortability

\section{INTRODUTION}

The ongoing process of urbanization in the world is accompanied by a concentration of population, industry, transport in small areas, leading to increased anthropogenic load on all components of the urban environment. Adverse environmental impacts of human activities taking place within this habitat have a negative impact on the health of urban populations. Within the structure of urban settlements, towns are an important element. About 70\% of modern Nigerian cities are small towns. However, many of the problems of these cities currently remain poorly understood or not studied at all.

A comprehensive assessment of municipal land is an insoluble problem for local authorities because of the high cost of existing methods and the lack of qualified specialists. There is need therefore for the development of clear criteria that might be used when evaluating municipal land. Therefore, the development of methodology for assessing municipal land for small towns, creation of the basis for urban land monitoring system, their typology based on the degree of comfort for the people living there, has become of particular relevance. The purpose of work is to develop a methodology for assessing municipal land using Obudu, Cross River Region - Nigeria as a case study, and to proffer recommendations for the further development of urban areas.

\footnotetext{
How to cite this article (APA): Ugbong, I. A., and Ukam, L. E. (2021). Developing Comprehensive Assessment and Monitoring Parametres for Lands in Small Towns - Focus on Obudu Town, Cross River Region, Nigeria. International Journal of Engineering Technologies and Management Research, 8(9), 60-69. doi: 10.29121/ijetmr.v8.i9.2021.1029
} 


\section{MATERIALS AND METHOD}

This research work is based on field studies and field observations conducted in Obudu, the study area, including cartographic and library materials, as well as materials from the Archives of the Cross River State Ministry of Lands and Housing. The study used the following methods and approaches: perceptual experiences, monitoring, generalizations, formalization, cartographic, historical, as well as comparative geographical and statistical analyses. A careful descriptive approach is adopted, using flow-chats and algorithms.

\section{THEORETICAL AND METHODOLOGICAL FOUNDATIONS FOR THE STUDY OF URBAN LAND}

This study considered the city as a geographic entity; it examines the conditions of formation of urban land, as well as methods for the study of the urban environment, and the technique of examination and evaluation of urban land. At the present study of urban land, much attention is paid to the ecological state of the urban environment and the extent of its pollution [Bukovsky (2006); Armstrong (1998)]. The term "urban environment", connotes different meanings to different people. According to Dotti (2016), "the urban environment is the totality of the urban population and their living conditions." According to Rezvani et al. (2013), "the urban environment is a complex of natural, man-made, and socio-economic factors that have a large and varied impact on the inhabitants of the cities."

Natural, technological and social components form the complex mix of an urban environment. All the factors are closely linked. It is their combination that has a general effect on humans. The absence of pollution is connected with the most important indicator for the residents of the urban environment - that is, its comfort. The comfort of the urban environment is a subjective feeling and an objective state of complete health dealing with environmental conditions of the human urban environment, including its natural and socio-economic indicators [Bukovsky (2006); Sizov (2006)]. According to Sizov (2006), "it is a component part of the comfort of urban areas - existing property do cause a subjective feeling and objective state of comfortable environment, providing for good health, including the comfort of visual, aural, olfactory states that are conducive to maintaining good health."

In addition, in the opinion of this paper, it is possible to allocate more number of natural (physical), man-made (anthropogenic) and public (social) performance indicators by which one can judge the quality of the urban environment and, consequently, about the extent of its comfort.

In the study of the status of urban land, a wealth of information of meaningful and quantitative nature is usually collected. As a rule, when a large number of indicators are heterogeneous in terms of information and extent, there is a need for the application of multivariate statistical analysis, which allows the hidden patterns that objectively exist in the urban environment to be explained.

In the classification of multi-dimensional objects, we use cluster analysis method that allows us to divide the objects in the featured space into group-clusters so that objects belonging to the same class are made close, and the objects of different classes are separated from each other. Cluster analysis methods make it 
possible to allocate discrete and compact subset of a continuum [Karkavin (2007); Gruzdeva (2005)].

The cost of municipal land in general is defined as usually external to the municipality factors. Many of these factors, by means of a number of generalizations can be reduced to two: (1) state of the environment in the region in general and (2) economic and geographical position of the municipality. The first defines the physical possibility of a prolonged stay in the territory without causing significant damage to health, and the second - the possible degree of social comfort.

However, the value of land within the municipality obviously cannot be the same. The basis for differentiation could be the integrated geo-ecological assessment of land of small towns. Thus the main criterion for the differentiated assessment of urban land is a comfortable urban environment. This research work developed a method of geo-ecological assessment of lands of small towns and classification of the degree of comfort of the urban environment. Schematic diagram of the procedure is shown in Figure 1.

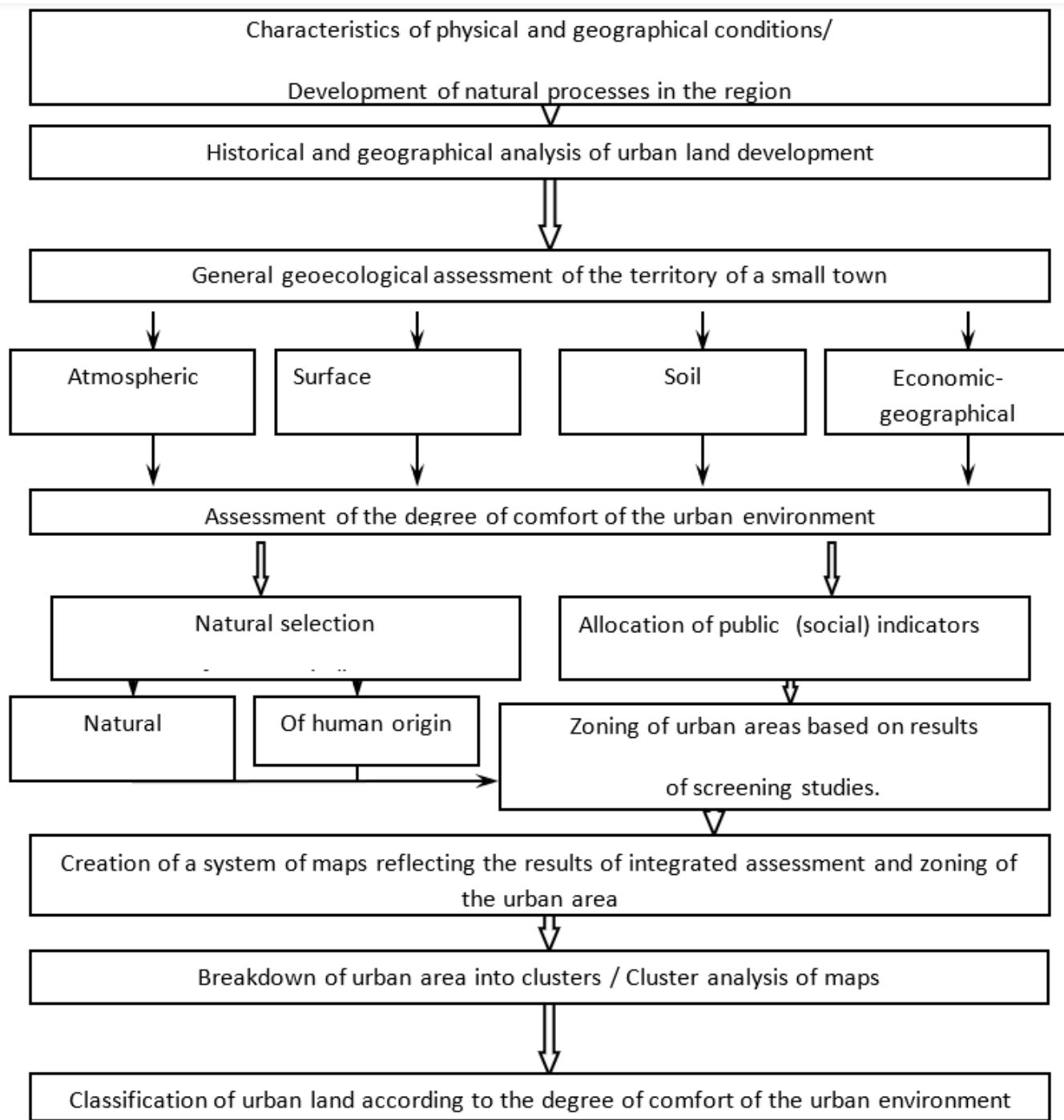

Figure 1 Algorithm for a comprehensive assessment of urban land and Classification on the degree of comfort of the urban environment 
The developed method of examination and evaluation of urban land includes the characteristic physical and geographical conditions for the development of natural processes in the region, the historical and geographical analysis of the urban land, the general geo-ecological evaluation of the city. Other components include, assessment of the degree of comfort of the urban environment, zoning of urban areas based on screening results, creating map-chart system reflecting the results of a comprehensive assessment of zoning and the urban areas, a breakdown of the urban area into clusters, then cluster analysis map-charts, and classification of the urban land according to the degree of comfort.

As a result of the cluster analysis of all map-charts, that is, all evaluation parameters in each cluster is a set of evaluation points, from there all evaluation parameters are analyzed. An integration of all component points defines degree of comfort of the urban environment (DCUE), calculated as follows:

$$
\tilde{N} \hat{E} \tilde{A} \tilde{N}=\sum_{1}^{i} \frac{k \times x_{i}}{i} \text {, where } \mathrm{x}=\text { the value of the estimated figure in points; }
$$

i - The number of performance indicators;

$\mathrm{k}$ - Correction factor.

Thus, an integral component in points is obtained for each cluster. On the basis of the values obtained for each of the selected clusters, an integral index of urban land on the degree of comfort of the urban environment is obtained and can be implemented on the relevant Schematic map.

It is proposed we evaluate the degree of comfort of the urban environment using at least ten natural and eight public features. It is obvious that the natural indicators have a direct impact on the health and comfort of living citizen. The influence of social factors is usually indirect. Therefore, in our opinion, in the calculation of the integral index of the degree of comfort of the urban environment (DCUE) using the estimated scores on social indicators, it is advisable to apply a correction factor $\mathrm{k}=0,5$.

Also as performance indicators of degree of comfort, we suggest using the following parametres: the degree of pollution of the atmosphere; the quality of tap water; anthropogenic load on the land and soil; noise level; and electromagnetic radiation background; possibility of flooding; type of building; condition of road surface; distance from the administrative center; distance from the nearest public transport; distance from the nearest school; distance from the nearest medical facility; distance from the ambulance station; distance from the fire brigade and rescue services; remoteness from industrial enterprises and industrial sites; distance from the major recreational facilities and sizes of plots of land.

\section{HISTORICAL AND GEOGRAPHICAL ANALYSIS OF THE FORMATION AND DEVELOPMENT OF LANDS IN SMALL TOWNS}

In the process of development of human civilization cities became the environment of life of more and more people. Initially, the urban environment is formed from the natural landscape by techno-genesis, i.e., first, by minor and then 
ever deeper anthropogenic components of the environment, followed by the emergence of new, non-peculiar natural complexes of the urban environment.

Considering the urban environment from the standpoint of a systems approach, it is necessary to integrate the concept of "urban environment" with "natural environment". And considering the factors that influence the urban environment, it is also necessary to talk about the system as "surrounding space". "Surrounding space" in this case is understood as natural (natural complexes of different taxonomic rank) and social (economic, social and political).

If at the dawn of the development of civilization the leading factors of the emergence and development of cities and, consequently, the urban environment were natural, then with the development of civilization the leading role began to move to the social, i.e. social, economic and political factors. At present, even the emergence of new cities is determined by economic feasibility.

In this regard, this work takes into account the study and evaluation of the processes of formation of both the urban environment as a whole and its individual components: i.e., different degrees of natural (water, phytocenosis, land), and anthropogenic (residential, industrial, office buildings and communications) components. It is also necessary to take into account the leading social (socio economic) factors.

The economic and geographical position (EGP) is an integral and at the same time the leading social factor in the formation and development of the urban environment, including its components of natural origin. According to M. E. Bukovsky, in consideration of the EGP characteristics of the city in the formation of its functional structure, it is necessary to see the implementation of certain aspects of geographical location. A. A. Kozlov believes that EGP should be recognized as the most important factor of regional development. This factor is historical, i.e. its impact on regional processes is constantly being transformed, and hence its impact is dynamic and tends to change.

\subsection{THE OBUDU URBAN EPISODE}

The exact time of occurrence of settlements at the site of modern Obudu town cannot be established. But the economic and geographical location factors at an early stage of development of the land and the villages of the neighborhood can be clearly understood. The town of Obudu is located on a low-lying Knoll and surrounded by beautiful scenic hills. It provided access to many rural communities and in time became a market center for agro-produce. The actual formation of modern Obudu as an urban area occurred during colonial times. Elementary urban areas, formed in the early stages of anthropogenesis are not preserved in the present structure. About $40 \%$ of the urban landscape was formed about the end of $19^{\text {th }}$ to the beginning of the $20^{\text {th }}$ century. Few existing relics define the architectural and historic character of the city, but they create problems of planning, both sanitary-hygienic and social. As a result of the changed geographical relations between the city and space, the functional structure of the city has been transformed many times. 


\subsection{GENERAL CHARACTERISTICS OF THE TERRITORY OF OBUDU TOWNSHIP}

Like in most towns in Nigeria, the degree of comfortability in any part of Obudu town is determined by security, availability of social amenities like pipe-born water, electricity, etc. The southern axis of the town is inhibited by aboriginal populations who live in small "urban villages" and share a common ancestral bond. There are five such urban villages - Bebuabung, Aboinkib, Bebuagam, Atiekpe and Bebuawhan. Here, planning is difficult because the territories are already built up, and in most cases, creating new access is a problem. The empty parcels of land that are lying behind residential areas are closed up by existing developments. The problem of access prevents new housing developments from such places.

The north-western axis is a zone of relatively newer development. Urbanization actually began here during the colonial era when European-styled architecture was introduced. There is a well-organized system of streets and housing layout, the gridpattern of street layout being most prominent. The central market is located between this zone and the southern axis. Most residents here are non-indigenes and migrants; and security is a problem, because residents do not know each other along family lines. But comfortability is fairly guaranteed by availability of amenities and a cleaner environment.

The north-eastern axis can be termed a zone of educational and administrative land use. Schools and tertiary institutions as well as hospitals are located here. The zone also serves as administrative headquarters of Obudu Local government area. A "green belt" was carefully planned between this zone and the southern axis by the colonial administration. This was probably due to the topography of that boundary area. There is a kind of cliff-edge on that stretch that could easily have led to serious gully erosion, if it was left unchecked. A city park was thus, created there, same as we have in much of Krasnodar city in Russia.

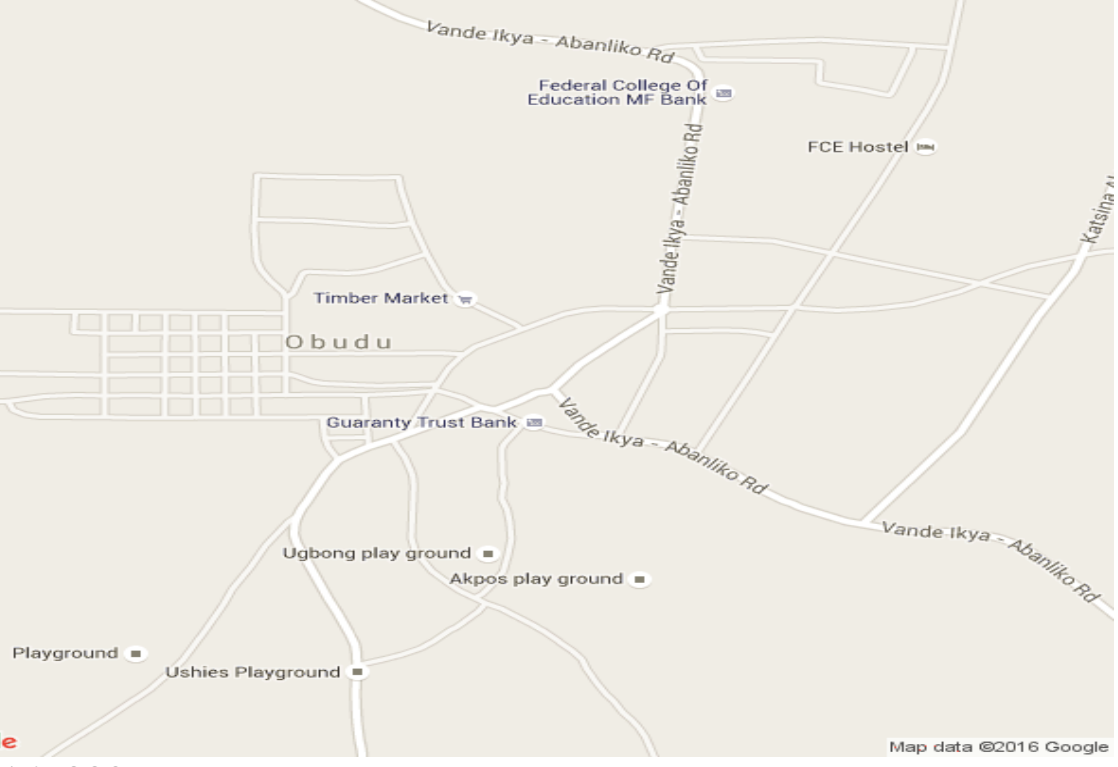

$6.66958,9.167829$

http://maps.googleapis.com/maps/api/staticmap?center=6.66958,9.167829\&zoo $\mathrm{m}=15 \& \mathrm{maptype}=$ roadmap $\&$ size $=640 \times 640 \&$ sensor $=$ false 


\section{ASSESSMENT, TYPIFICATION AND MONITORING OF URBAN LAND}

The principles of geo-ecological mapping involve carrying out zoning of urban areas based on the results of screening, cluster analysis of the obtained maps, and typification of urban land on the degree of comfort of the urban environment. Also proposed is a flow-sheet creation of urban land monitoring system and recommendations for optimization and development of the urban areas.

In solving the problem of complex geographical mapping of the urban environment, we follow V.Z Makarov, Chiara and Pavan (2018), and Marans and Stimson (2011), who proposed adherence to certain methodological orientations and approaches. In general terms, the following set of basic principles can be formulated: geosystems, ecosystems, historicism, and geography (Figure 2).

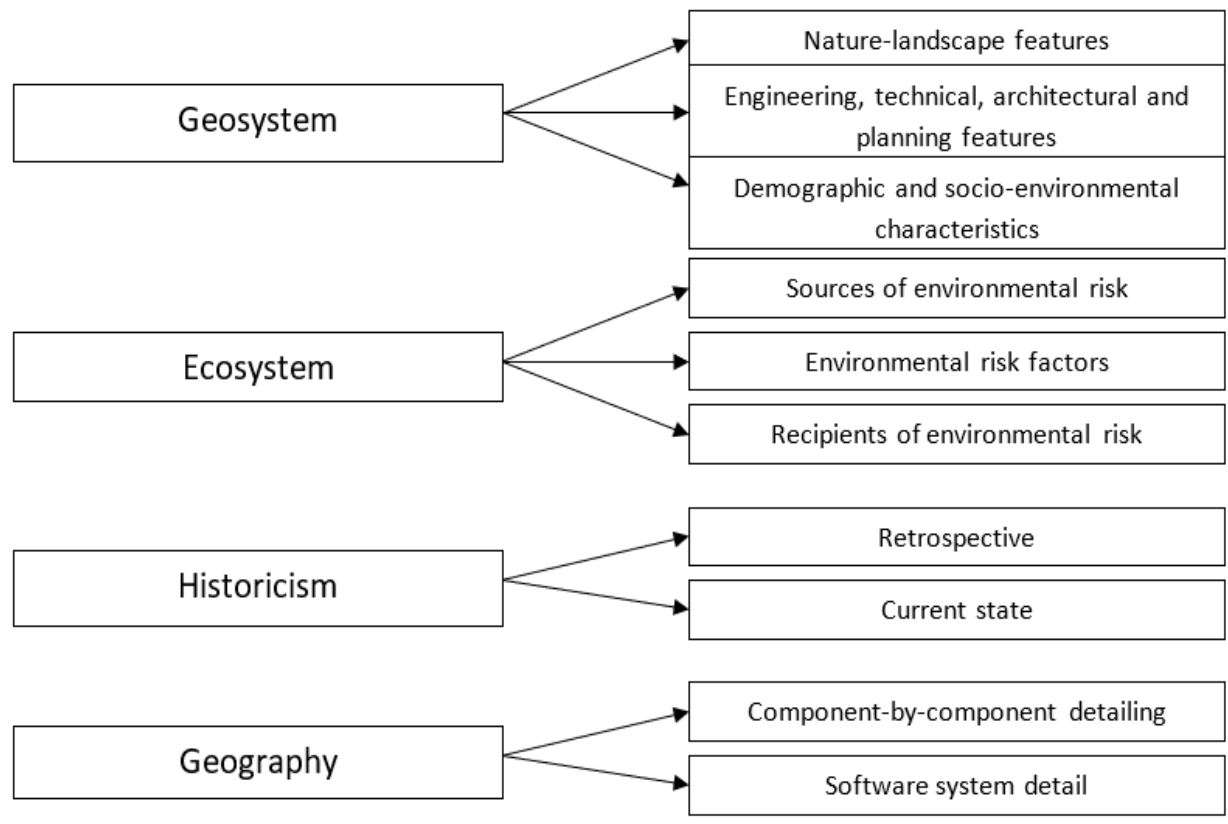

Figure 2 Principles of integrated geographical mapping of cities.

In order to classify urban land according to the degree of comfort in the urban environment we also propose the use of a system of performance indicators and evaluation criteria for each evaluation index in points. In order to carry out such geo-ecological assessment and zoning of the city on every performance indicator, a series of screening areas of Obudu township are proposed. The evaluation can be conducted using the method of ball-point based on the criteria developed.

In the course of zoning the city for a number of natural and social performance indicators, it was revealed that in general the part of the city with the lowest scores were those with low "quality of water supply." Accordingly, indicators such as total hardness and iron content (total), were higher than the absolute majority of the MPC sample. Also systematically exceeding MPC limits were such indicators as the turbidity (in kaolin) and chromaticity. There is an urgent problem citywide for the quality of water supplied to the population. This problem is majorly a consequence of the abandonment of Municipal water supply infrastructure by successive administrations. The major water intake point has been the lower end of the Abeb 
river. Before the total abandonment of this this facility, urban developments at the upper segment of the river had caused massive inflow of domestic wastes into the river, and with poor water-treatment equipment, there was bound to be equally very poor water quality. Reliance was therefore, largely on individual bore-holes which suffered limitations from the natural features of the exploited artesian aquifers. Recent action by the current state administration by relocating the intake point to the upper segment, at the Obudu Dam site is a step in the right direction. Although this effort has not led to guaranteed "tap water supply", it is hoped that further steps will be taken to ensure adequate flow of clean tap water to the urban residents. This also calls for urgent modernization of the municipal water intake facility and construction of iron removal plants at such city water intakes.

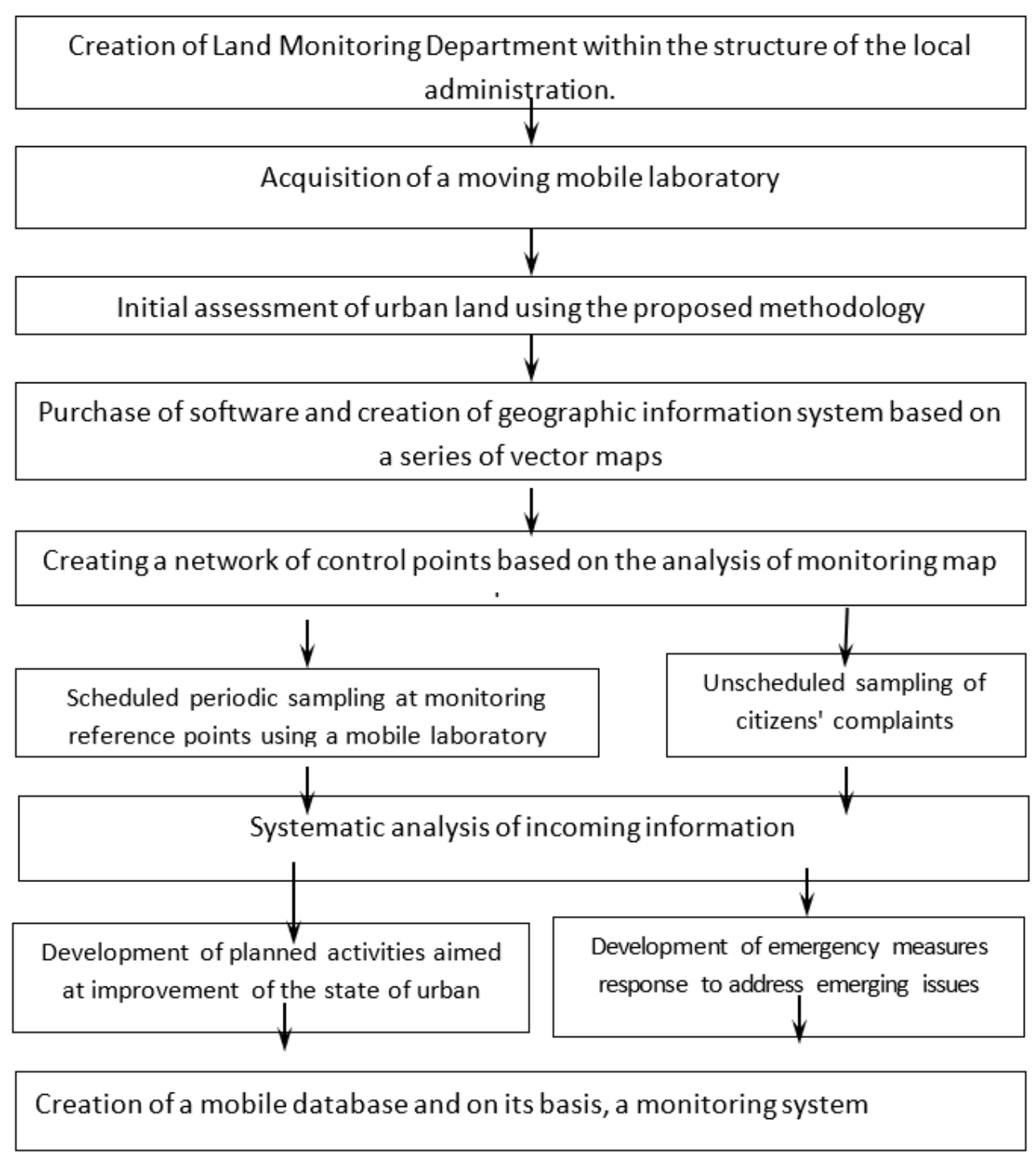

Figure 3 Technological scheme of creating a land monitoring system of small town.

Also, mostly low grades in the whole city during its zoning have been received on such indicators as "anthropogenic load on soil and land" and "State of the pavement of streets." We propose a compilation of Schematic map of "State of the Pavement of Streets", which will allow the officials of the local administration to 
identify priorities in the repair of roads and sidewalks in the city streets. The difficult problem of anthropogenic load on soil and land arises mostly from the lack of a centralized sewage as most of the territory is occupied by the private homeowners. And urban villages. As a result, removal of fecal water from even low-rise buildings in the city is carried out in backyard pit latrines. Here municipal authorities need to pay close attention to the development and monitoring of the sewerage, as well as a storm water drain system for the city.

The main source of air pollution in the city is transportation. The greatest intensity of movement of motor transport is marked by the transit through city streets. In our view, the re-direction of transit traffic to bypass the urban area will significantly improve the situation and reduce emissions. The latest effort at the development of the city should follow the Master Plan which provides for the construction of a bypass road around the city. It is necessary to start construction of this road at this phase. Also it was revealed that local pockets of air pollution occurred at the traffic congestion at closed crossings in at the city centre. These and more are some of the problems confronting the urbanized areas and require urgent attention.

\section{CONCLUSIONS}

In conclusion, the urban environment should be viewed as an integral phenomenon, created by the action of many factors and having several components. Initially, the urban environment is formed from the natural landscape by technogenesis. First small, and then ever more profound anthropogenic components of the natural environment, followed by the emergence of new, nonpeculiar natural urban environmental complexes. Formation of the modern Obudu urban landscape occurred over a period of about two centuries. Elementary urban areas were formed in the early stages of anthropogenesis, which were not preserved in the present structure. About $40 \%$ of the urban landscape formed at the end of XIX and the beginning of the XX century. They define the architectural and historic character of the city, but create problems of planning, sanitation, hygiene and social malaise.

Finally, we propose the methodology of assessing the degree of comfort of the urban environment using ten (10) to eight (8) natural and anthropogenic indicators. These performance indicators are as follows: the degree of air pollution; the quality of tap water; anthropogenic load on soil and land; noise level; and electromagnetic radiation background; possibility of flooding and floodwater; type of building; condition of road covering the streets; distance from the administrative center; distance from the nearest public transport system; distance from the nearest school; distance from the nearest medical facility; distance from the ambulance station; distance from the fire brigade and rescue services; remoteness from industrial enterprises and industrial sites; distance from the major recreational facilities; and the sizes of plots of land.

\section{REFERENCES}

Armstrong M (1998). Fundamentals of Management. How to become a better leader. - Rostov-on-Don: Phoenix, - 512 p.

Bukovsky M.E (2006) The public component of the formation of urban environment in "the City system and surrounding areas, example of Maures Shan" // 
Bulletin of the University of Tambov. Series: Natural Sciences. - Volume 11, no. 4. - pp. 525-529.

Bukovsky M.E (2007) Methods of study and geo-ecological assessment of lands of small cities / M. E. Bukovsky // Problems of modern science and practice. number 3 - p. 31-36.

Chiara Garau and Valentina Maria Pavan (2018), Evaluating Urban Quality: Indicators and Assessment Tools for Smart Sustainable Cities, in Sustainability February, Retrieved from https://www.mdpi.com/journal/sustainability. https://doi.org/10.3390/su10030575

Dotti, G. (2016) How to Measure the Quality of Life in Smart Cities?. Available online: http://phys.org/ news/2016-04-quality-life-smart-cities.html (accessed on 21 December 2017).

Gruzdeva L.P (2005)Monitoring of the urban environment and nature in the small cities of Russia / Land management, cadastre and monitoring of lands. - № 11. - p. 98 - 99.

Gruzdeva L.P (2004) Strategic Planning: studies. manual / Ed. prof. AN Petrova. SPb.: Knowledge. - 200 p.

Karkavin M.V (2007)Strategic analysis in the planning of sustainable ecological and economic development of a large city // Russian Entrepreneurship. - № 10 Vol. 2 (100). - C. 184-189. - Retrieved from http://www.creativeconomy.ru/articles/12244/

Marans, R.W., Stimson, R. (2011)Investigating quality of urban life: Theory, methods, and empirical research. Soc. Indic. Res, 45, 1-29. Retrieved from https://doi.org/10.1007/978-94-007-1742-8_1

Rezvani, M.R., Mansourian, H.; Sattari, M.H. (2013) Evaluating quality of life in urban areas. Soc. Indic. Res., 112, 203-220. Retrieved from https://doi.org/10.1007/s11205-012-0048-2

Sizov A.P (2006)Urban Earth: Quality Assessment, monitoring, application of their results in the Land Use Regulation. Theses for the degree of Doctor of Technical Sciences, Moscow. 